\title{
Concepções dos cuidados em saúde mental por uma equipe de saúde da família, em perspectiva histórico-cultural
}

\author{
The concept of mental care \\ of a family health team from a historical-cultural perspective
}

Marcelo Dalla Vecchia ${ }^{1}$

Sueli Terezinha Ferreira M artins ${ }^{2}$

\footnotetext{
${ }^{1}$ Programa de PósGraduação em Saúde Coletiva, Faculdade de Medicina, UNESP.

Distrito deRubião Junior s/ n. 18618-970 Botucatu SP. mdvecchia@yahoo.com.br ${ }^{2}$ Departamento de Neurologia, Psicologia e Psiquiatria, Faculdade de Medicina, UNESP.
}

\begin{abstract}
The present study aims at analyzing the individual senses and social meanings of mental care actions carried out by professionals working in a Family Health Care Team. The study is based on Vigotsky's (1896-1934) theoretical perspective of a historical and cultural psychology. The work is part of a participant research and as such conducted in the context of a field research. It was observed that the team took into consideration the relevance of social determinants for the disease of the target population, the need for making use of diversified care strategies reaching beyond the clinical setting, the importance of taking care of their own mental health, as well as difficulties related to approaching the families of the patients. We emphasize the importance of overcoming the exclusiveness of the biomedical de termination of the health-disease process as pointed out in theoperational principles of theFamily $\mathrm{H}$ ealth Care Strategy, expressed by responsiveness as a care tool, the establishment of relationships and continued care.
\end{abstract}

Key words Family health, M ental health, Primary care, Historical and cultural psychology, Individual senses and social meanings
Resumo 0 presente estudo visa a analisar sentidos pessoaisesignificações sociais das atividades deatenção em saúde mental desenvolvidas por profissionais integrantes de uma equipe de saúde da família. Parte-se, para tal, da perspectiva teórica da psicologia histórico-cultural de Vigotsky (1896-1934). 0 trabalho é parte de uma pesquisa participante e, portanto, écontextualizado na etapa deinserção no campo. Observou-se que a equipe considera relevante a determinação das condições de vida no processo saúde doença da população atendida, a necessidade de lançar mão de estratégias diversificadas no cuidado para além da consulta, a importância desecuidar da saúde mental da própria equipe, bem como dificuldades na abordagem da família. Indica-se a importância, para o trabalho cotidiano das equipes, das possi bilidades de superação da exclusividade do núcleo biomédico na determinação do processo saúdedoença apontadas nos princípios operacionais da Estratégia de Saúdeda Família, expressas na utilização do acol himento como recurso de cui dado, a constituição de vínculos e responsabilização e a continuidade da atenção.

Palavras-chave Saúde da família, Saúde mental, Atenção básica, Psicologia histórico-cultural, Sentidos pessoais e si gnificações sociais 
Introdução

A articulação da atenção bási ca a uma rede substitutiva de cuidados à saúde mental tem se estabelecido como uma das diretrizes históricas para a consolidação da reforma psiquiátrica brasileira, que reitera a centralidade da constituição de dispositivos de base comunitária eterritorial enquanto equipamentos importantes para que se supere a iatrogenia da assistência à saúde mental hospitalocêntrica.

A Declaração de Caracas, de 1990, éum marco nesse processo em nível internacional, ao notar que "a atenção psiquiátrica convencional não permite alcançar os objetivos compatíveis com uma atenção comunitária, descentralizada, participativa, integral, contínua e preventiva".

Estudos sistemáticos e experiências municipais e regionais no contexto do SU S vêm demonstrando a importância da efetivação das diretrizes de descentralização e territorialização, bem como a estruturação das ações de saúde com base em equipesmultiprofissionais especializadas em saúdemental que possam, minimamente, assegurar retaguarda para as equipes atuantes na atenção básica ${ }^{1-4}$. Não se deve desconsiderar, porém, que no período precedenteà institucionalização jurídico-política do SUS - fundamentalmente a partir do período da "distensão gradual e progressiva" da ditadura - registram-se experiências que forneceram importantes fundamentos teórico-práticos àquelas que seriam desenvolvidas posteriormente ${ }^{5-8}$.

Com a adoção da Estratégia de Saúde da Família (ESF) como eixo para a reorganização da atenção básica em novas bases assistenciais ${ }^{9}$, consolidada mais recentemente na Política Nacional de Atenção Básica, as equipes têm sido instadas a atuarem frente a questões como dependência química, depressão e violência doméstica, de alta pre valência na população em geral. Na medida em que a adscrição da clientela em base territorial é um dos princípios operacionais da gestão do processo de trabalho na estratégia de saúde da família, o vínculo e a continuidade do cuidado tendem a gerar um confronto cotidiano dos profissionais atuantes neste nível de atenção com questões relacionadas a tais demandas

Do ponto de vista da atividade prática cotidiana dos profissionais atuantes em equipes de saúde da família, ocorrequea população da área deabrangência lhes demanda respostas assistenciais em saúde mental para as quais, por um lado, não existem ações programáticas correspondentes na atenção básica previstas nos instrumentos degestão e plane jamento e, por outro, podem consistir em deman- da espontânea de caráter de urgência ou emergência, requerendo a utilização de estratégias adequadas, por exemplo, na ameaça/tentativa de suicídio.

Onocko-Campos ${ }^{10}$ indica a necessidade, na Saú de Coletiva, deuma clínica que dêconta deacoIher as demandas do sujeito em situação de crise psiquiátrica em todos os níveis do sistema de saúde como dispositivo fundamental para romper o ciclo de psiquiatrização e medicalização do sofrimento psíquico. A ambulatorização da demanda éum dos riscos neste processo, podendo-se recair na denominada psiquiatrização dos problemas sociais, ou seja, a porta de entrada do sistema de saúde, tratando-se, na verdade, em somente um espaço de triagem para a atenção especializada, ou ainda, limitando-se a uma clínica cujo foco é a patologia11.

No presenteartigo, apresenta-seo relato de uma pesquisa que busca explicitar as práticas de cuidado em saúde mental realizadas por uma equipe de saú de da família. Entende-se que tais práticas encontram-seintimamente relacionadas com acúmulos anteriores representados pelos aspectos da formação e experiência precedentes, formais e informais. Tornam-se particularmenteimportantes para esta análise as ocasiões em que, justamente, o cotidiano do trabalho impõeaos profissionais da equipe um questionamento a respeito da sua própria formação e suas experiências precedentes.

A perspectiva adotada no trabalho em relato parte das premissas adotadas por L. S. Vigotsky (1896-1934) e seus seguidores no questionamento da ausência de uma psicologia que parta de um enfoque materialista, histórico e global do psiquismo humano e, portanto, da subjetividade. Considera-se, desta forma, a psicologia como uma ciência concreta, tendo sempre (implícita ou explicitamente) uma base filosófica. Parte-se do pressuposto que o comportamento humano não se encontra separado do desenvolvimento histórico geral ${ }^{12}$.

Na medida em que esta análise situa-se no desenvolvimento de uma pesquisa participante, consiste na etapa de levantamento de necessidades para um trabalho em saúde mental realizada juntamente com a equipe, para o que se considerou importante identificar as concepções relacionadas às práticas de atenção à saúde mental no cotidiano do trabalho.

\section{Marcos teórico-metodológicos}

Em decorrência da forma de adaptação e do caráter social da sua atividade, diferentemente dos demais seres vivos, a relação do ser humano com a natureza não se dá somente no sentido de desen- 
volver ações práticas voltadas à satisfação imediata de necessidades biológicas. São caracteristicamente humanos: a organização social do trabalho; a intencionalidade consciente das ações - uma pré ideação, tel eológica e interna, da realidade e das finalidades das suas atividades -, e o uso de meios indiretos (ferramentas e signos) para realizá-los, tendo em vista a satisfação de necessidades também subjetivas, psicológicas, mediatas, descoladas, na maioria das vezes, de seu caráter imediato.

Inspirado nos fundamentos teórico-metodológicos e epistemológicos do marxismo, Vygotski indica que a superação do materialismo vulgar e do idealismo em psicologia deve levar em conta que, para resolver os problemas postos para prática e investigação psicológica, a tarefa de análise deve ser entendida como uma investigação pensante $^{13}$. Assim, não deve se restringir à descrição da aparência do fenômeno psicológico, aos seus traços emanifestações externas, atentando, porém, para que no momento explicativo se incorpore a investigação de relações e nexos dinâmico-causais em sua origem real.

Para tal, parte-se de uma analogia: a atividade humana depende de instrumentos, sendo mediada por meio de ferramentas, para a satisfação de necessidades, sejam elas do estômago ou da fantasia: o primeiro fato histórico é pois a produção dos meios que permitem satisfazer as necessidades, a produção da própria vida material [...] U ma vez satisfeita a primei ra necessidade, a ação de a satisfazer e o instrumento utilizado para tal conduzem a novas necessidades e essa produção de novas necessidades constitui o primeiro fato histórico ${ }^{14}$.

Os signos, estruturados em sistemas lingüísticos de representação (a linguagem, as diferentes formas de numeração e cálculo, mapas, diagramas, obras de arte, etc.), adquirem o valor de instrumentos psicológicos ao converterem-se, através da atividade prática, em portadores de significações sociais determinadas. N este processo de apropriação da realidade na consciência, de constituição de um reflexo psíquico consciente, os significados se estabilizam enquanto representações da realidade e, comunicados socialmente na forma da fala, objetivam-se, orientando intencionalmente a atividade consciente do ser humano, dando sentido a ela.

Conforme Leontiev, a imagem do reflexo psíquico se manifesta em toda a sua riqueza como experimentando em si aquele sistema de relações objetivas no qual existe real mente o conteúdo por ela refletido. Com maior razão isso se refere à imagem sensível consciente, à imagem do reflexo consciente do mundo ${ }^{15}$. Nesta abordagem teórica da formação do psiquismo humano, a consciência individual é, portanto, uma forma especificamente humana de reflexo subjetivo da realidade objetiva, caracterizada também pela parcialidade, ou seja, a imagem sensível do reflexo psíquico é conscientizada enquanto parte da realidade, cujo movimento é independente da existência ou percepção deste movimento pelo ser humano.

Vigotsky sintetiza este processo dialético de apropriação e objetivação ao afirmar que os signos são criações artificiais culturais da humanidade e seguem uma lógica particular de desenvolvimento: dirigem-se primeiro "para fora" através da atividade social prática, voltam-se para o ser humano como reflexo psíquico da realidade para, então, desenvolverem-seinternamente, propiciando a constituição de sentidos pessoais ${ }^{16}$. Este desenvolvimento, porém, não se dá no vazio, na medida em que cumpre uma específica função social: a comunicação, estabelecida com base em compreensão racional e na intenção de transmitir idéias e vivências, exige necessariamente um sistema de meios cujo protótipo foi, é e continuará sendo a linguagem humana, que surgiu da necessidade de comunicação no processo de trabalho' ${ }^{16}$.

Leontiev ${ }^{15}$, na mesma direção, acrescenta que no processo da produção material os homens produzem também sua linguagem, que lhes serve não somente como meio de comunicação, senão também como portadora dos valores socialmente criados, fixados nela.

Em termos concretos, como a linguagem pode ser um recurso para a produção de conhecimento sobre as práticas em saúde mental realizadas por uma equipe de saúde? N esta perspectiva teórica, como se compreende o papel da palavra na constituição da consciência e, portanto, como a análise do conteúdo de entrevistas pode apoiar no entendimento de como a equipe compreende tais práticas, nesta perspectiva?

No processo de socialização, no qual os indivíduos tomam contato com a realidade concreta e seus signos e com as outras pessoas e se comunicam, os significados adquirem, para cada indivíduo em particular, a forma de sentidos pessoais, expressando a unidade dinâmica de processos intelectuais e afetivos. Vigotsky, ao estudar a formação do pensamento verbal, sintetiza essa relação entre os sentidos esignificações sociais da seguinte maneira: Tomada isoladamente no léxico, a palavra tem apenas um significado. $M$ as este não émais que uma potência que se realiza no discurso vivo, no qual o significado éapenas uma pedra no edifício do sentido $0^{16}$.

Leontiev, em outra ocasião, discute que o con- 
teúdo e a função social do signo se transformam no decorrer do desenvolvimento histórico da humanidade e, portanto, os processos de produção e reprodução social determinam diferentemente as circunstâncias e as formas de apropriação e objetivação, pelos indivíduos, dos signos e, assim, dos sentidos e significações sociais da sua atividade no mundo. $\mathrm{N}$ as condições da sociedade de classes, ocorre um afastamento da maioria dos indivíduos com as possibilidades de plena realização das suas necessidades, determinando níveis diferenciados de apropriação dos instrumentos e, portanto, dos signos disponíveis e historicamente acumulados, em conformidade com o lugar que o indivíduo ocupa no processo geral de produção e apropriação do trabalho social. Este processo, objetivamente colocado, reflete-se psiquicamente frente às contradições da vida humana nas circunstâncias da sociedade de classes, criando o que 0 autor denomina os problemas de consciência ou contradições da consciência: em essência, o desenvolvimento desigual e paralelo dos sentidos pessoais e das significações sociais ${ }^{17}$.

$\mathrm{Na}$ pesquisa na abordagem histórico-cultural, a apreensão do significado da fala enquanto unidade do pensamento e da linguagem implica adotar a palavra com significado como unidade deanálise ${ }^{18}$. Neste processo, é possível a identificação de núcleos de significação, que expressam formas e conteúdos de realização dos sentidos pelos indivíduos a partir de sua prática concreta e sua inserção sócio-histórica: a fala, construída na relação com a história e a cultura, e expressa pelo sujeito, corresponde à manei ra como este é capaz de expressar/codificar, neste momento específico, as vivências que se processam em sua subjetividade; cabeao pesquisador o esforço analítico de ultrapassar essa aparência (essas formas desi gnificação) eir em busca das determinações (históricas e sociais), que se configuram no plano do sujeito como motivações, necessidades, interesses (que são, portanto, individuais e históricos), para chegar ao sentido atribuído/construído pelo sujeito ${ }^{18}$.

Identificar núcleos de significação implica que o pesquisador, porém, não se atenha tão somente à dimensão da análise sintática da palavra expressa no discurso, considerando, também, que a linguagem contém os registros sociais, produzidos historicamente ( significados), mas contém, também, os re gistros pessoais, com as dimensões subjetivas correspondentes: ações, cogni ções, afetos ${ }^{19}$.

A observação participante foi adotada como estratégia para apoiar a identificação dos núcleos de significação, com o acompanhamento de visitas domiciliares em situações avaliadas como de inte- resse da área de saúde mental, reuniões de equipe, observação em sala de espera eatividade em grupo deapoio com alcoolistas. Recordando o queaponta Cruz N eto ${ }^{20}$ em relação à observação participante, a importância dessa técnica reside no fato de podermos captar uma variedade de situações ou fenômenos que não são obtidos por meio de perguntas, uma vez que, observados diretamentena própria realidade, transmitem o que há de mais imponderável e evasivo na vida real.

Cabe, finalmente, apontar em linhas gerais 0 processo concreto de análise que se empreendeu na presente pesquisa. 0 objeto deste estudo, como já foi indicado, são as práticas de produção de cuidados em saúde mental realizadas por uma equipe de saúde da família.

Por intermédio de leituras exaustivas das entrevistas semi-estruturadas realizadas com todos os membros da equipe pesquisada, empreendeuseuma análise de conteúdo na modalidade deanálise temática ${ }^{21} \mathrm{com}$ a finalidade de identificar os núcleos de significação das práticas de produção de cuidados em saúde mental para a equipe em particular: o que emerge do discurso na qualidade degeneralizações, enquanto conceitos, representações, concepções a respeito de tais práticas, considerando a atividade concreta e cotidiana desta equipe de saúde?

Entende-se que éfundamental discutir os sentidos pessoais destas práticas para os profissionais da equipe, individualmente considerados, tendo por referência os núcleos de significação identificados: as concepções sobre as práticas realizadas permitem identificar em que medida, ou como, estas respondem às suas necessidades enquanto apropriação e objetivação dos bens culturais historicamente acumulados e a efetiva realização de seus potenciais humanos?

Neste processo, entende-se ser possível aprimorar a compreensão em torno dos motivos que determinam a forma particular de produção de cuidados em saúde mental pela equipe, construindo-se um quadro analítico abrangente em relação aos sentidos e significações sociais destas práticas. Este quadro pode, por sua vez, subsidiar o planejamento de ações que, dentre outros objetivos, levem em conta a formulação de políticas de cuidado em saúde mental na atenção básica.

\section{Desenvolvimento da pesquisa}

Com a aprovação do Comitê de Ética em Pesquisa da Faculdade de M edicina de Botucatu/Unesp, o projeto foi apresentado em reunião da coordena- 
ção municipal da ESF de um município de médio porte do interior do Estado de São Paulo. U ma das equipes presentes nesta reunião manifestou interesse em participar de levantamento de necessidades para um trabalho em saúde mental, ao informar que problemas de saúde relacionados (depressão, al coolismo, violência doméstica, etc.) têm sido significativos na sua área de abrangência. Preservados os dispostos da Resolução n 196/1996 do Conselho Nacional de Saúde, consentiu-se pelo início da pesquisa participante juntamente a esta equipe.

Como recurso inicial para a fase de levantamento de necessidades enquanto etapa exploratória da pesquisa, realizou-se a sistematização de informações relacionadas aos seguintes aspectos: a) equipes da ESF constituídas no município; b) localização das áreas de abrangência; c) contexto e início das atividades ed) número e categoria profissional dos componentes das equipes.

0 município contava com equipes que atuavam em Unidades deSaúde da Família (USF) construídas especificamente para o início das atividades, com a coexistência decentros locais estruturados a partir de ações programáticas realizadas em Unidades Básicas de Saúde (UBS). A abrangência territorial da população de referência das U BS foi reformulada com o início das atividades das equipes daESF contando, no período de realização deste estudo (agosto a dezembro de 2004), com aproximadamente um ano e seis meses de implantação. Pode-se aventar que houve ampliação da cobertura assistencial para a atenção básica, na medida em que as equipes localizam-se em regiões perifé ricas e de urbanização recente com maiores barreiras para 0 acesso, considerando-se, pelo menos, 0 aspecto da proximidade físico-geográfica.

É possível que a complexa rede de assistência médico-hospitalar disponível no município tenha minimizado a necessidade de implantação mais imediata de uma estratégia de atenção primária cujo maior impacto vem sendo observado, efetivamente, em regiões que anteriormente não contavam com nenhum tipo de assistência, como no N ortee N ordeste do país ${ }^{9}$. A constituição das equipes seguia de maneira bastante estrita as recomendações do M inistério da Saúde em termos do número mínimo de profissionais e sua categoria de origem, no período do estudo: a equipe pesquisada contava com um profissional médico e um de enfermagem, dois auxiliares de enfermagem, seis agentes comunitários de saúde (ACS), um auxiliar administrativo e um auxiliar de serviços gerais.

Durante os primeiros contatos com a equipe, a coordenadora (enfermeira) informou que ações relacionadas ao cuidado em saúde mental vinham sendo realizadas na unidade: grupo de artesanato, grupo de alcoolistas, acompanhamento terapêutico com portadores de depressão, grupo de caminhada. Destacou, também, al gumas das dificuldades que depois seriam constatadas nas entrevistas, como: a necessidade de um suporte profissional mais específico, a necessidade de formação na área de saúde mental, as dúvidas edificuldades em relação ao encaminhamento paraa atenção especializada quando necessário.

Antes da realização de cada entrevista, solicitou-se 0 fornecimento de informações destinadas à caracterização da população pesquisada: foram entrevistados os doze membros da equipe, cujos componentes eram, em sua grande maioria, do sexo feminino $(91,7 \%)$, com uma média de 29,2 anos deidade, tendo $75,0 \%$ cursado o nível médio, $8,3 \%$, superior incompleto e $16,7 \%$, pós-graduação. Também em termos médios, contavam com 3,1 anos de experiência na profissão e 1,8 anos de atuação na ESF.

Ainda que não se tenha contado com informações comparativas das outras equipes constituídas no município, pode-seafirmar ser uma equipecuja faixa etária indica a predominância dejovens adultos, com pouco tempo de experiência na profissão e que, na sua maioria, têm na ESF uma primeira oportunidade de trabalho. Considerando-se que metade da equipeéformada por ACS equeo início de sua atividade na equipe foi concomitante à implantação da ESF no município, observa-se que a média de 0,8 ano detempo deexperiênciana profissão e de atuação na ESF sugere certo nível de rotatividade dentreestes profissionais. Além disso, consiste em um subgrupo ainda mais jovem da equipe pesquisada, com média de 25,8 anos de idade.

H ouve registro integral das entrevistas realizadas, com posterior transcrição, adotando-se também um protocolo de observação participante, com registro em diário de campo, constituindo-se ambos no corpus desta etapa da pesquisa.

A entrevista semi-estruturada partiu da seguinte pauta: 1) histórico profissional anterior à inserção do profissional na ESF, com ênfase na experiência relacionada à saúde mental (cursos, treinamentos, formação acadêmica, experiência pessoal, etc.) ; 2) a inserção em uma equipe da ESF (processo da sel eção, acolhimento na equipe, percepções e expectativas em relação ao trabalho); 3) cursos e treinamentos realizados enquanto componente de uma equipe da ESF no que se trata à formação para a promoção, prevenção, assistência e reabilitação em saúde mental; 4) percepções, sentimentos, opiniões a respeito de pessoas com transtornos mentais e em condição de sofrimento psíquico, bem 
como da sua relação com os familiares e, destes, com a equipe; 5) encaminhamentos instituídos pela equipe em relação a estes casos, bem como seu manejo cotidiano, além das principais possibilidades percebidas e dificuldades enfrentadas.

\section{Análise desentidos pessoais esignificações sociais}

A presenta-se, a seguir, o processo de análise desentidos pessoais esignificações sociais. Os nomes atribuídos aos entrevistados são fictícios, para a garantia de sigilo e anonimato. Tendo em vista que a representatividadenumérica não éum fator determinante na natureza da análise empreendida, não se traz em relevo a origem profissional dos entre vistados, sem prejuízo para os objetivos postos. Os trechos de falas, como se observará, são destacados como recurso para ilustrar a análise realizada.

Inicialmente, nota-sequeum dosnúcleos designificação emergentes consiste na concepção de que condições de vida são importantes determinantes do processo saúde-doença da população adscrita.

Em diversas ocasiões, os profissionais observam que as práticas de cuidados em saúde mental dependem da articulação de um conjunto de condições, como a própria organização do sistema de atenção à saúde e o acesso aos equipamentos sociais. Expressam uma compreensão do sofrimento psíquico enquanto também sendo influenciado por tais condições, não seguindo um curso "natural", na medida em que diversas doenças são também determinadas por componentes psicossociais.

Algumas fal as evidenciam esta questão: A gente encontra muitos obstáculos, né? Às vezes não dá pra ajudar as pessoas do jeito que a gente queria, né? Aí entra tudo, assim. As dificuldades financeiras das pessoas, da remuneração e moradia. É coisa que não dá pra gente interferir muito, né? M uitas vezes, eu me sinto frustrada de ver as pessoas passando necessidade(Glória).

Então eu acho que o impacto mesmo só os grupos, o vínculo entre a comunidade, entre eles mesmos. Queé a potencialidadeque cada um tem. E na consulta a gente sempre procura estar dando este enfoque da vida social, dos problemas, do que incomoda (Leandra).

A gente conhece toda a família da pessoa e vê se pode ser realmente saúde mental. 0 que está afligindo a pessoa pra ela estar fazendo aquilo. A grandemaioria édepressão. M uita depressão relativa à família, marido, problema na vida. A maioria dos casos (Isabel).

Conseqüências de muito desencadeante externo. Agressão, perda familiar, em razão de desemprego.
M uito contexto ruim que vai pressionando as pessoas e elas vão adoecendo (Karina).

Há, porém, sentidos diversos e contraditórios entre si se analisarmos mais atentamente tais assertivas: para Glória, isso implica esbarrar em circunstâncias que são praticamente impossíveis de mudar ("não dá pra interferir muito, né?"); Leandra considera que se trata de uma questão iniciativa do profissional ("a gente sempre procura estar dando este enfoque"), enquanto para Isabel e Karina as condições de vida permitem identificar cau sas suficientes para o adoecimento ("depressão relativa a problema na vida, contexto ruim que pressiona").

Outro núcleo designificação emergente refere-se à importância de recorrer a uma diversidade de estratégias não restritas à consulta. Referem, desta forma, à necessidade de utilizar uma variedade de re cursos (atividades em grupo, estratégias de educação em saúde, visitas domiciliares, etc.), além da medicação, para possibilitar o cuidado integral à saúde, inclusive de pessoas com transtornos mentais.

À medida que você vai tirando da pessoa o que é que é melhor pra ela é que a gente vai conseguindo achar soluções, né? Depois é difícil você colocar na cabeça da pessoa que se ela ir pra um lugar desses [CAPS] ela vai obter um tratamento. D e uma terapia ou de um trabalho de um artesanato, de alguma coisa que vai mel horar. Porque el es estão muito acostumados ao remédio. Tomar Diazepan, tomar calmante e dormir, entendeu? (M aria).

Aqui é uma das unidades onde os auxiliares coordenam grupos, os agentes comunitários coordenam grupos. Isso eu acho que é um pouquinho já do trabalho de educação em saúde que eles priorizam. Eu acredito que a saúde mental seja trabalhada em grupo e na conversa (Leandra).

Eu não sei se eu vejo errado. Mas a sensação é que, por exemplo, os pacientes [psiquiátricos] não estão melhorando, não há uma intervenção, assim, de discussão, abrir aquele caso, sei lá: põe mais um remédio. Aí fica quatro, cinco, seis remédios. A minha sensação éque só está enrolando o paciente. Essa é a minha sensação. Eu não tenho conhecimento pra dizer que é isso (Karina).

Aqui, também, os sentidos atribuídos à utilização de estratégias diversas no cuidado são heterogêneos. M aria considera que diversificar as estratégias éum desafio ( "el es estão muito acostumados ao remédio"); Leandra, que o trabalho de educação em saúde é também um recurso para o desenvolvimento dos profissionais ("os auxiliares coordenam grupos, os agentes comunitários coordenam grupos") e, para Karina, diversificar as estratégias possibilita ampliar a resolutividade ereduzir a iatrogenia (discutir o caso, abrir o caso). 
Um terceiro núcleo designificação queilustra a diversidade de sentidos conferidos aos significados das práticas deatenção à saúde mental da equipe refere-se à necessidade de atenção à saúde mental dos próprios profissionais da equipe. Indicam, neste sentido, encontrarem-se muitas vezes sobrecarregados em ouvir e conversar sem dar encaminhamento ou solução para determinadas demandas verificadas no cotidiano do trabal ho, sensibilizando-se com as necessidades das pessoas. A demanda por um espaço que possibilite a discussão do trabalho cotidiano e não se restrinja aos procedimentos administrativos éexpressa deforma mais significativa pelos agentes comunitários:

Porque agora que a gente chega ali, no meio do povo, é diferente. Você vê que é diferente. Tem as dificuldades, tem muita coisa. Doença, pessoas passando necessidade. Então é, não éfácil [ voz embargada] (Ismélia).

Então é trabalhar um pouco nós, um pouco a nossa cabeça, pra descarregar um pouco. Pra gente estar preparado depois pra encontrar o problema lá fora. Porque se você está carregado, como você vai receber do outro? (M aria)

Porque chega em casa, assim, meia... Porque pega, né? Porque mais que a gente tente não pegar, a gente acaba pegando um pouco pra gente. Eu, pelo menos, me falta experiência (Glória).

Ismélia, bastante sensibilizada, se expressa no sentido de que o contato mais próximo com a população implica em cotidianamentetomar consciência das suas muitas necessidades ( "doença, pessoas passando necessidade"). Para M aria, énecessário um espaço para desabafar ("trabalhar um pouco nós, um pouco a nossa cabeça") e Glória consideraquea própria experiência cotidiana exerceriaum fator de proteção à sua saúde mental.

Chama a atenção a diversidade de sentidos e significados presentes na questão do papel da família no cuidado de pessoas com transtornos mentais, não sendo possível identificar um núcleo de significação que permita abranger uma concepção relativamente uniforme da equipe a este respeito: (a) consideram que a família às vezes adoece junto, por encontrar-se sobrecarregada com as necessidades de cuidados intensivos ou ainda por não saber como lidar com a sintomatologia do transtorno mental, mostrando-se muitas vezes impacientes ou agressivos com o familiar; (b) vêem como uma dificuldade a população entender como funciona o tratamento e o próprio contato com a pessoa em sofrimento psíquico: fica trancado em casa, é impaciente com outras pessoas; (c) relatam não haver nenhum trabalho planejado da equipeneste sentido, mas expressam sua necessidade.
Tem caso de família que o tratamento com eles é muito, muito bom. $M$ as tem caso que é extrema rejei ção. N esses casos de rejeição, não éa família quem procura [a USF]. É alguém defora quevem nos procurar, sabe? Porque a família está maltratando. A família já não procura por isso (Isabel).

A família sofre muito. Primeira coisa que você acha: entrou em surto, é porque a família não está dando a medicação. Que não está cuidado direito. M as o papel do cuidador é muito difícil. Eu não sei trabalhar muito bem com esses sentimentos que geram no contexto familiar, que é super complicado. $\mathrm{N}$ a medida do possível, eu ajudo com as orientações e ao estar ao lado (Leandra).

Quando as pessoas começam um tratamento, eu falo, assim, no caso do alcoolismo. A família tem que, é junto. Pra ajudar, pra incentivar, pra lembrar da reunião. Pra ver como é que é. A família tem que estar em conjunto (Glória).

Há outros doisnúcleos designificação que, tanto por terem sido mencionados por praticamente todos os entrevistados, quanto pela relevância que possuem enquanto características centrais da estratégia de saúde da família, contribuem de forma importante na compreensão das concepções a respeito das práticas em saúde mental da equipe. 0 primeiro deles consisteno significado atribuído ao acolhimento como recurso terapêutico:

É que a gente já tem um vínculo, né? Então a gente já pergunta como está, pergunta como é que está a medicação. Então é por aí que a gente entra. Aí a pessoa começa a relatar. $\mathrm{E}$ aí, a gente tem que ir entrando, assim. Às vezes com o pai, com a mãe, pra perguntar (Maria).

Às vezes a pessoa senta pra conversar com a gente e você vê que ela não quer levantar. A pessoa tem carência de sentar e ficar conversando aqui com a gente. Às vezes não énada. Q uantos eu não falo: "ah, dona Maria. Vai lá, toma um chazinho" (Isabel).

Pergunto, pergunto, pergunto; pergunto, pergunto, pergunto. Seeu vejo quea pessoa está sefechando, se ela não responde pra mim, né? Aí eu relaxo. Começo a pergunta de outra forma, né? Q uando ela dá abertura pra eu perceber o que está afligindo ela, aí eu consigo perceber. Se é uma depressão, se é, né? Geralmente, a pessoa, na terceira palavra, ela já começa a chorar e a pessoa já vem se entregando, né? Ela já vem querendo conversar (Ester).

Outro núcleo que expressa uma unidade importante em torno de sentidos e significados consiste na questão da constituição de vínculos, responsabilização e continuidade nos cuidados em saúde:

Pra essa partedesaúdemental foi bom [refere-se à ESF]. Porque é mais fácil a gente ir lá, abordar e 
saber o porquêdisso. Porqueàs vezesa pessoa não...são muitas barreiras que a gente tem que atravessar. É difícil. N ossa! A gente não tem aquele apoio que pre cisaria, né? (J oana).

Não na primeira visita, mas depois de algumas visitas que a pessoa pega um pouquinho de confiança, aí ela se abre. Aí ela fala quetem problema com o marido queéalcoolista. Conta um caso que se passa. (Renata).

Pra nós, agentes comunitários, o paciente de saúdemental parecequeelesprendem maisa gente. Parece que eles prendem mais. É que nem os acamados. A gente fica mais preocupado, assim, com eles (M aria).

A necessidade de cuidar de perto (acompanhando, às vezes, diariamente), o uso da conversa como recurso terapêutico (saber ouvir, dar uma atenção especial, aten der com calma e paciência) , a importância de colocar-se no lugar da pessoa e de tratar a pessoa em sofrimento psíquico como qualquer outra pessoa para que seja possível adquirir confiança e constituir vínculos, entre outras questões assinaladas acima, são viabilizadas por conta da própria forma de organização da assistência suscitada pela estratégia de saúde da família.

Entende-se que, nesta questão, há um sentido que se apresenta com uma relativa unidade com relação às concepções do cuidado em saúde mental pela equipe, distintamente dos demais núcleos de significação elencados: a saúde da família enquanto possibilidade de ruptura com o núcleo exclusivamente biomédico de abordagem do processo saúde-doença.

Desta forma, seja em razão do próprio processo de acolhimento ser significado como um momento terapêutico, seja em razão da organização do trabalho viabilizar um acompanhamento continuado de problemas de saúde, pode-se observar que o sentido de ampliação da percepção das ne cessidades em saúde suscitada pela estratégia de saúde da família está presente com homogeneidade relevante.

\section{Discussão}

Foi possível observar, durante a realização das entrevistas, que as questões relacionadas à atenção à saúde mental mobilizavam inúmeras preocupações por parte de todos os entrevistados, independentemente desua origem funcional na equipe. Tais preocupações se expressam desde a sensação de despreparo para lidar com o sofrimento psíquico até os temores relacionados com a possi bilidade de que sintomas agressivos fossem deflagrados durante as visitas domiciliares.
Tomando-se o conjunto da produção de cuidado em saúde mental da equipe, nota-seque, efetivamente, não há formação e experiência precedente à sua inserção na ESF e sistematizada pela grande maioria dos seus membros, com exceção de momentos pontuais na formação dos profissionais de nível superior. 0 trabalho da equipe, porém, revela-se permeado por demandas que requerem práticas de atenção à saúde mental.

A parentemente, nota-se forte incorporação ideológica dos princípios da reforma sanitária e da reforma psiquiátrica brasileira, ainda que de forma fragmentada, sinalizando, porém, condições favoráveis para a promoção da atenção à saúde mental em base comunitária:

A gente gostaria muito de um treinamento de saúde mental, porque é uma coisa muito legal. Eu acho muito legal e as meninas também sempre falam. Porque a gente está muito perto. Então, isso daí, seria um pouco nós. Trabalhar nós um pouco pra resolver essa situação ( $M$ aria).

Projeto, assim, de atividade, de arte, estas coisas. E é importante este tipo de atividade pra desenvolver, pra trabalhar as mulheres, né? Q ue às vezes você vê que está entrando em um quadro de depressão. A gente tenta ajudar com esses recursos. Porque ajuda. Bastante (Renata).

No trabalho cotidiano, até onde se pôde perceber através da análise das entrevistas, a atenção diferenciada dispensada a pessoas com transtornos mentais é significada na sua subordinação ao caráter generalista da produção de relações de cuidado, independentemente das especificidades de um projeto terapêutico-pedagógico de cuidado à saúde mental. N estas circunstâncias, há uma tendência em se considerar uma abordagem ampliada do processo saúde-doença, incluindo dimensões psicossociais e os determinantes da condição de vida da população da área de abrangência na identificação de situações que demandam atenção em saúde mental pela equipe estudada.

Os relatos permitem observar, também, que 0 recurso ao especialista em saúde mental éconsiderado relevantea partir desituações avaliadas como de urgência e na necessidade de instrumentalização técnica e apoio com discussão de casos, ressalvadas as situações que, antes mesmo da abertura da USF, já vinham sendo acompanhadas na atenção especializada.

É possível observar iniciativas importantes no sentido de se evitar a internação psiquiátrica através do acompanhamento dos egressos, orientação aos familiares e esforço para evitar a medicalização do sofrimento psíquico. Especificamente em relação ao cuidado na família, os entrevistados rei- 
teram as dificuldades cotidianas vivenciadas por familiares cuidadores de pessoas com transtornos mentais que têm sido informadas por vários estudos $3,22-27$.

Nota-se, além disso, que há uma importância atribuída a problemas relacionados aos encaminhamentos para a atenção especializada, ao questionamento do diagnóstico realizado, ao desconhecimento da proposta da estratégia de saúde da família por parte da população e à necessidade de suporte especializado para a equipe:

Às vezes o pessoal reclama quea gente... Às vezes vem e não consegue atendimento. Porque é puxado: são quase cinco mil pessoas pra duas pessoas. Assim, bem dizer, a médica e a enfermeira (Joana).

Eles estavam acostumados à U nidade Básica de Saúde. Que nem, eles iam no [bairro] e lá tem um profissional pra cada coisa. 0 gi necologista, o pediatra etudo. Aqui tem um profissional só, queégeral e que atende a todos, tanto a criança, como 0 adulto, como qualquer coisa (Renata).

Eu gostaria muito de ter discussão de caso dínico. Assim, de ter uma equipe com quem a gente pudesse discutir os casos complicados. M esmo que não fosse pra gente seguir, se fosse pra gente encaminhar, mas que a gente pudesse ter um mínimo de manejo daquilo (Karina).

A parentemente, no que tange aos cuidados em saúde mental, pessoas que demandam atenção especializada já vinham sendo acompanhadas. No seu conjunto, porém, a equipe refere não contar com instrumentos técnicos que possibilitem discriminar, pelo menos de forma mais imediata, as situações que podem ser cuidadas por profissionais generalistas e aquelas em que há necessidade deencaminhamento especializado.

Em decorrência de os determinantes e fatores de proteção da condição de sofrimento psíquico não serem tão imediatamente evidentes e/ou apreensíveis e na medida em que o cuidado de pessoas em sofrimento psíquico tende a se estender no decorrer do tempo, exigindo diversas ações intermediárias, afirma-se ser mais difícil tratar de outros problemas de saúde quando está presente o sofrimento psíquico.

\section{Considerações finais}

Quando se analisam as formas pelas quais as condições de vida da população são apontadas enquanto determinantes do processo saúde-doença, é justamente 0 fato de se deparar cotidianamente com o enfrentamento das dificuldades socioeconômicas da população atendida que parece impli- car esta percepção ampliada. Na medida em que a área de abrangência da equipeéuma região perifé rica e de urbanização recente, cujos moradores, de uma maneira geral, são operários de indústrias da região e trabalham na lavoura, identificar as condições de vida traz a constatação aos profissionais de que há circunstâncias que são impossíveis de mudar, sabendo-as determinantes de processos de adoecimento.

Ainda que seja extremamenteimportante queo processo saúde-doença seja devidamente contextualizado frenteàs condições de vida, inclusivecomo forma de se ampliar a percepção de necessidades em saúde e as próprias possibilidades de assistência, há um risco que é permanente nesta situação, queé o de naturalização de tais circunstâncias, que poderiam ser vistas como eternas, imutáveis e não enquanto determinadas por uma específica forma de organização social. Na medida em que as possibilidades de mudar são dadas pela necessidade de ações intermediárias, não-imediatas, a tendência é que se remeta à sua impossibilidade.

A própria abertura para outros recursos para além do enquadreclínico da consulta possibilitada pela forma de organização do trabalho na ESF contribui para esta percepção ampliada, ao passo que a equipe procura diversificar as estratégias de assistência oferecendo, além das consultas, atividades em grupo e outras atividades comunitárias, bem como incorporando cotidianamente as visitas domiciliares também enquanto estratégia de assistência. Tomar consciência das inúmeras dificuldades que a população atendida vivencia neste processo é também uma fonte de sofrimento para os profissionais, o que fica evidente quando, nas entrevistas, se referem à saúde mental da própria equipe. $A$ fala de uma agente comunitária é muito ilustrativa neste sentido:

De repente você consegue tirar da família que 0 problema dela éque ela não tem nada pra comer. Aí você chega aqui no posto e fala. E daí aonde nós vamos recorrer? $N$ ão tem assistente social que possa dar uma cesta básica, entendeu?É uma luta grande. Então tem certas circunstâncias que nós agentes ficamos entrea cruz ea espada. A gentenão sabe como resolver, né? É muito tumultuado, né? Essas coisas. Pra nós.

Ao mesmo tempo, visualizam que a possibilidade de constituir espaços onde possam discutir o próprio processo de trabalho pode minimizar 0 sofrimento vivenciado com este contato muito imediato com as circunstâncias que produzem adoecimento. Com efeito, estudos têm apontado que estratégias educativas e terapêuticas na forma de supervisões externas são eficazes no sentido de 
acolher questões entendidas pelos profissionais enquanto necessidade de "descarregar" ou cujo enfrentamento pode ser potencializado através da reflexão sobre sua atividade cotidiana ${ }^{28-31}$.

Esta questão remete também à discussão a respeito dos limites e possibilidades colocados para os processos de formação e de educação permanente dos profissionais. A "entrada em cena" das condições de vida da população na determinação do processo saúde-doença, bastante evidente na estratégia de saúde da família, impõe aos profissionais um processo de instrumentalização em torno de habilidades e competências necessárias para o cuidado em saúde, em que é relevante a necessidade de ampliação do núcleo biomédico de determinação do processo saúde-doença.

Se, por um lado, isso requer o que é entendido como mudança de atitude, a própria diversificação das estratégias de assistência exige um processo de desenvolvimento profissional que não se observou estar sendo realizado de forma sistemática e que poderia auxiliar no desafio de superar uma cultura medicocêntrica e de medicalização do sofrimento.

É relevanteindicar também quea análise apontou muito claramente como a equipe, pelo menos até onde se pode notar através das entrevistas e da observação participante, ainda vivencia dificuldades quanto à abordagem da família, seja em situações em que está presente o sofrimento psíquico, seja en quanto unidade de cuidado à saúde de uma forma geral:
A minha grandepergunta éessa: seéatendimento de família, a gente não faz. Q uando é que a gente vai fazer atendimento de família? N ão dizem que PSF éatendimento de família? N ão faz. N ão faz. I sso é só idéia, né? Com o tempo, eu acho, assim, podeser que, sem querer pode ser que a gente vá conhecendo todo mundo e faça a interligação.

$\mathrm{N}$ a medida em que a equipe iniciou suas atividades em umaárea queanteriormente contava com barreiras geográficas importantes para o acesso, é possível cogitar que necessidades "escondidas" de atenção à saúde sejam identificadas e demandem resolutividade mais imediata no atendimento de uma população anteriormente não adscrita pelo sistema de saúde.

Finalmente, considera-se ser possível observar que o vínculo e a continuidade da atenção evidenciam cotidianamente para a equipe que os cuidados em saúde mental requerem uma abordagem ampliada, sendo significados na mediação de condições sociais como o trabalho, as relações intrafamiliares e 0 apoio social e comunitário. 0 acoIhimento como recurso terapêutico e o vínculo e continuidade da atenção enquanto possibilidades de ruptura com a exclusividade do núcleo biomédico na determinação do processo saúde-doença têm sido destacados por al guns estudos enquanto uma potencialidade importante da estratégia de saúde da família ${ }^{32,33}$, o que também se verificou no presente trabalho.

\section{Colaboradores}

M Dalla Vecchia eSTF M artins participaram igualmente de todas as etapas da elaboração do artigo. 


\section{Referências}

1. Amaral MA. Atenção à saúde mental na rede básica: estudo sobre a eficácia do modelo assistencial. Rev. Saúde Pública 1997; 31(3):288-295.

2. Lancetti $A$, organizador. Saúde M ental e Saúde da Família. São Paulo: Hucitec; 2000.

3. Brêda MZ, Augusto LGS. O cuidado ao portador de transtorno psíquico na atenção básica de saúde. Cien Saude Colet 2001; 6(2):471-480.

4. Pitta AM F, organizadora. Reabilitação psicossocial no Brasil. 2a ed. São Paulo: Hucitec; 2001.

5. Silva RC. 0 trabalho do psicólogo em Centros de Saúde: algumas reflexões sobre as funções da Psicologia na atenção primária à saúde [tese]. São Paulo (SP): Instituto de Psicologia; 1988.

6. Cesarino AC. U ma experiência de saúde mental na Prefeitura de São Paulo. In: Lancetti A, organizador. Saúde Loucura 1. São Paulo: Hucitec; 1989. p. 3-32.

7. Fernandes MA, Vicentin MCG, Vieira MC. Tecendo a rede: trajetórias da saúde mental em São Paulo 19891996. Taubaté: Cabral; 1999.

8. Amarante P, Torre EHG. A constituição de novas práticas no campo da Atenção Psicossocial: análise de dois projetos pioneiros na Reforma Psiquiátrica no Brasil. Saúde em Debate 2001; 25(58):26-34.

9. Brasil. M inistério da Saúde. Programa Saúde da Família: ampliando a cobertura para consolidar a mudança do modelo de atenção básica. Revista Brasileira de Atenção M aterno-Infantil 2003; 3(1):113-125.

10. Onocko Campos RT. Clínica: a palavra negada. Sobre as práticas clínicas nos serviços substitutivos de saúde mental. Saúde em Debate 2001; 25(58):98-111.

11. Alves DSN, Guljor AP. O cuidado em saúde mental. In: Pinheiro R, M attos RA, organizadores. Cuidado: as fronteiras da integralidade. São Paulo: Hucitec; Rio de Janeiro: IM S-UERJ/Abrasco; 2003. p. 221-240.

12. Leontiev AN. Artigo de introdução sobre o trabalho criativo de L. S. Vygotsky. In: Vygotsky LS. Teoria e método em psicologia. $2^{\underline{a}}$ ed. São Paulo: Martins Fontes; 1999. p. 425-470.

13. Vygotski LS. Historia del desarollo de las funciones psíquicas superiores. In: Vygotski LS. Obras escogidas III. Madrid: Visor; 1995. p. 47-119.

14. Marx K, Engels F. A ideologia alemã. 2a ed. São Paulo: Livraria Editora Ciências Humanas; 1979.

15. Leontiev AN. Actividad, conciencia, personalidad. Habana: Pueblo y Educación; 1975.

16. Vygotsky LS. A construção do pensamento e da linguagem. São Paulo: M artins Fontes; 2001.

17. Leontiev AN. Sobre o desenvolvimento histórico da consciência. In: Leontiev AN. O desenvolvimento do psiquismo. Lisboa: Horizonte Universitário; 1978. p. 89-142.

18. Aguiar WMJ. A pesquisa em psicologia sócio-histórica: contribuições para o debate metodológico. In: Bock AMB, Gonçalves M GM, Furtado O, organizadores. Psicologia sócio-histórica: uma perspectiva crítica em psicologia. São Paulo: Cortez; 2001. p. 129-140.
19. Gonçalves M GM . O método de pesquisa materialista histórico e dialético. In: Abrantes AA, Silva NR, Martins STF, organizadores. M étodo histórico-social na psicologia social. Petrópolis: Vozes; 2005. p. 86-104.

20. Cruz Neto 0. O trabalho de campo como descoberta e criação. In: M inayo MCS, organizadora. Pesquisa social: teoria, método e criatividade. 12a ed. Petrópolis: Vozes; 1999. p. 51-66.

21. M inayo MCS. 0 desafio do conhecimento: pesquisa qualitativa em saúde. 7ạ ed. São Paulo: Hucitec; Rio de Janeiro: Abrasco; 2000.

22. Tsu T. A internação psiquiátrica e o drama das famílias. São Paulo: EDUSP/Vetor; 1993.

23. Moreno V. Vivência do familiar da pessoa em sofrimento psíquico [tese]. Ribeirão Preto (SP): Escola de Enfermagem de Ribeirão Preto; 2000.

24. M elman J. Família e doença mental: repensando a relação entre profissionais de saúde e familiares. São Paulo: Escrituras; 2001.

25. Rosa L. Transtorno mental e o cuidado na família. São Paulo: Cortez; 2003.

26. Ribeiro M BS. Estudos de características familiares de usuários de uma associação civil para a reabilitação psicossocial [dissertação]. Botucatu (SP): Faculdade de M edicina de Botucatu; 2003.

27. Dalla Vecchia M, Martins STF. O cuidado de pessoas com transtornos mentais no cotidiano de seus familiares: investigando o papel da internação psiquiátrica. Estudos de Psicologia (N atal) 2005; 11(2):159-168.

28. Peduzzi M, Palma JJL. A equipe de saúde. In: Schraiber LB, N emes MIB, M endes-Gonçalves RB, organizadores. Saúde do adulto. Programas e ações na U nidade Básica. São Paulo: Hucitec; 2000. p. 234-250.

29. Reis CCL, Hortale VA. Programa Saúde da Família: supervisão ou convisão? Estudo de caso em município de médio porte. Cad Saúde Pública 2004; 20(2):492-501.

30. M atumoto $S$, Fortuna CN, M ishima SM, Pereira MJB, Domingos NAM. Supervisão de equipes no Programa de Saúde da Família: reflexões acerca do desafio da produção de cuidados. Interface (Botucatu) 2005; 9(16):9-24

31. Silva IZQJ, Trad LAB. O trabalho em equipe no PSF: investigando a articulação técnica e a interação entre os profissionais. Interface (Botucatu) 2005; 9(16):25-38.

32. Schmith MD, Lima MADS. Acolhimento e vínculo em uma equipe do Programa Saúde da Família. Cad Saúde Pública 2004; 20(6):1487-1494.

33. Gomes M CPA, Pinheiro R. Acolhimento e vínculo: práticas de integralidade na gestão do cuidado em saúde em grandes centros urbanos. Interface (Botucatu) 2005; 9(17):287-301.

Artigo apresentado em 08/07/2007

Aprovado em 10/10/2007

Versão final apresentada em 18/10/2007 